\title{
The Idea of Lean Hospital
}

\section{Sogand Tourani ${ }^{1^{*}}$}

${ }^{1}$ School of Health Management and Information Sciences, Iran University of Medical Sciences, Tehran, Iran

*Corresponding Author: Sogand Tourani, Associate Professor, Ph.D. in Health Services Management, School of Health Management and Information Sciences, Iran University of Medical Sciences, Tehran, Iran. Email: sogandtourani@yahoo.com

$\mathrm{T}$ oday "lean production" is a tested and confirmed method effective in the success of industries like hospitals. To survive in global markets and increase competitiveness, however, an approach beyond the boundaries of the hospital is required. Moving from "lean production" to the idea of "lean hospital" can be more effective on excellence. As Keyte and Locher noted in their book "Lean Organization," 90\% of waste happens out of the production and service delivery sector. They further emphasize the need to focus on this waste. ${ }^{1}$

The result of the emergence of this view is a pure hospital known as "Lean Transformation." In this view, the application of lean principles and tools is developed and evolves from the production cell to the value stream and eventually to the hospital level because of the emergence of rapid changes and increasing complexities in the field of health care business. Therefore, in the course of lean hospital evolution, a comprehensive approach for the use of lean tools using a comprehensive management system is required. ${ }^{2}$

A lean hospital is a network of hospitals where a hospital is partnered with other hospitals to develop its capability to deliver value to patients in the form of a business cooperation network and through the development of resources, capacities, and capabilities. They are involved in creating added value in providing health care services to patients, hospitals, and all partners. In this regard, it is necessary for the lean hospital to focus on the lean principles in the supply chain. ${ }^{2,3}$

The idea of a lean hospital represents a monolithic organization which creates value for its various stakeholders by applying lean principles, practices, and techniques. The lean hospital approach integrates all stakeholders in the process of leaning and introduces a new way for hospitals to identify and assess value. The value stream between stakeholders and the internal and external network relations of hospitals are also considered in this approach. ${ }^{2,4}$

This system is rooted in the 2 key principles of continuous improvement and stakeholder dignity. The principle of continuous improvement includes tools and methods for improving efficiency; stakeholder dignity includes those classes of managerial behaviors and business practices of organizations that aim to eliminate waste and create value for customers. In fact, the principle of continuous improvement is the pursuit of perfection originating from the 5 principles of lean thinking. The guiding principle of response is associated with environmental changes and the need for agility and responsiveness to market opportunities. ${ }^{5}$ In lean hospitals, the principle of effective relationships across the value chain is based on mutual respect and trust, the sharing of information, and the open and honest communication of staff, patients, suppliers, and partners.

Today's lean hospitals face challenges including how to improve the total efficiency of the hospital, how to identify the needs of diverse stakeholders, how to establish a balance to meet the needs, and how to remove waste with the aim of creating value in the lean hospital. In fact, it can be claimed that the ultimate reason for the organization is to create value for the principal stakeholders. Stakeholders of a lean hospital can be the employees (internal customers), patients (external customers), hospital shareholders, business partners, suppliers, associations, societies, other hospitals, and so on. Therefore, each hospital can face a long list of individuals, groups, and other organizations that affect it. ${ }^{2,6}$

Obviously, the effectiveness of each of stakeholders is not equal with the other; therefore, to analyze and prioritize stakeholders, the "power-interest network" (a method which helps to analysis stakeholders) should be used. In this network, the stakeholders are categorized on the basis of effectiveness to the organization on the one hand and the interest and attention to it on the other hand. Thus, four different groups of stakeholders will be created, and policy-making management should be done with different approaches for each one (Figure 1). ${ }^{6}$

\section{Conflict of Interest Disclosures \\ None.}

\section{Ethical Approval}

Not applicable.

Copyright $\odot 2017$ The Hospital Practices and Research. This is an open-access article distributed under the terms of the Creative Commons Attribution License (http://creativecommons.org/licenses/by/4.0), which permits unrestricted use, distribution, and reproduction in any medium, provided the original work is properly cited. 


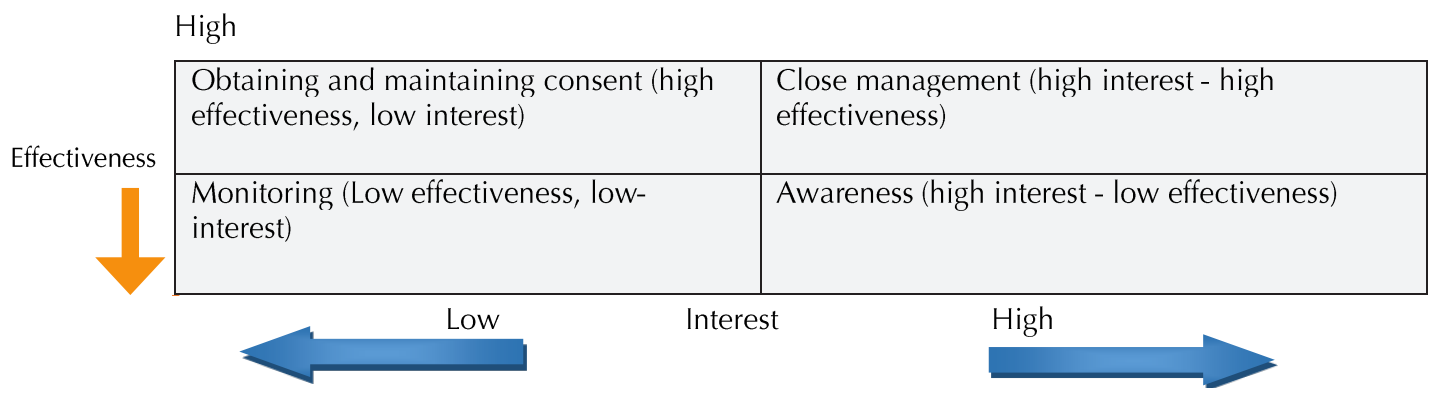

Figure 1. Prioritization of Stakeholders in the Power-Interest Network.

\section{References}

1. Keyte B, Locher D. The Complete Lean Enterprise. New York: Productivity Press; 2004.

2. Turani S. Lean Hospital Management. Tehran: Ebadifar publications; 2012. [Persian].

3. Jordan MS. Pulling Widgets into Lean Success. Ind Eng. 2003;35(3):34-39.
4. Womack J, Jones DT, Roos D. The Machine That Changed the Word. New York: MacMillan; 1990.

5. Lean Aerospace Initative (LAI). Massachusetts Institute of Technology. http://ssrc.mit.edu/programs/lean-advancementinitiative-lai.

6. Nightingale D. Enterprise Value Stream Mapping at MIT. Cambridge: MIT LAI; 2002. 